\title{
ANALISIS BENTUK ARANSEMEN LAGU ANOMAN OBONG CIPTAAN RANTO EDI GUDEL UNTUK PADUAN SUARA KARYA V. MANGUNSONGS
}

\section{Tendian Febriagazi}

\section{Sunarto}

Pendidikan Seni Drama Tari dan Musik Universitas Negeri Semarang

\section{Article \\ Information}

Article History

Received Oktober 2020

Approved November 2020

Published Desember 2020

Kata Kunci:

bentuk, aransemen, paduan suara, folklore, anoman obong

Keywords:

form, arrangement, choir, folklore, anoman obong
Abstrak

Lagu Anoman Obong ciptaan Ranto Edi Gudel adalah salah satu lagu yang menggunakan bahasa Jawa. Lagu ini diaransemen ke dalam format paduan suara oleh V. Mangunsongs. Dengan pengemasan yang lebih menarik, karya ini dapat digunakan sebagai salah satu pelestarian musik daerah Indonesia. Penelitian ini bertujuan untuk mendeskripsikan bentuk aransemen lagu Anoman Obong ciptaan Ranto Edi Gudel untuk paduan suara karya V. Mangunsongs. Penelitian ini menggunakan pendekatan kualitatif dengan metode analisis isi (content analysis). Pengumpulan data dilakukan melalui metode observasi, wawancara dan dokumentasi. Wawancara dilakukan terhadap narasumber yang berkompeten di bidang ini sekaligus aranger lagu Anoman Obong yaitu V. Mangunsongs alias Eko Agus Kandung. Tahap-tahap dalam menganalisis data adalah dengan reduksi data, penyajian data dan penyimpulan. Keabsahan data diperoleh melalui teknik triangulasi sumber data. Secara keseluruhan, aransemen lagu Anoman Obong ciptaan Ranto Edi Gudel untuk paduan suara karya V. Mangunsongs memiliki 111 ruang birama. Bentuk aransemen ini adalah termasuk free or group forms dengan Introduksi (birama 1-24) - Bagian A (birama 25-35) - Bagian A' (birama 35-43) - Bagian B (birama 44-58) - Interlude (birama 58-66) - Transisi (birama 67-86) Bagian B' (birama 87-101) - Postlude (birama 101-111). Di dalam karya ini, terdapat banyak perubahan tempo dan perubahan tanda dinamika untuk menunjang suasana kisah dan tragedi Anoman Obong. Hasil penelitian menunjukkan bahwa karya ini dapat mentransformasikan lagu vokal yang sebelumnya sederhana menjadi bentuk paduan suara yang lebih kompleks.

\footnotetext{
Abstract

The song Anoman Obong by Ranto Edi Gudel is a song that uses Javanese. The song was arranged into a choir format by V. Mangunsongs. The arrangement by V. Mangunsongs in the song Anoman Obong is unique, one of which is the combination of story and tragedy in the form of a SATB choir. This study aims to describe the form of the arrangement of the Anoman Obong song composed by Ranto Edi Gudel arranged for the choir by V. Mangunsongs. This study uses a qualitative approach with content analysis methods. Data collection was carried out through observation, interview and documentation methods. Interviews were conducted with competent speakers in this field as well as the aranger of Anoman Obong's song, namely V. Mangunsongs aka Eko Agus Kandung. The stages in analyzing data are data reduction, data presentation and conclusion. The validity of the data was obtained through the data source triangulation technique. Overall, the Anoman Obong song composed by Ranto Edi Gudel arranged for the choir by V. Mangunsongs has $111 \mathrm{bar}$ rooms. The form of this arrangement is including free or group forms with Introductions (bar 1-24) - Part A (bar 25-35) - Part A '(bar 35-43) - Part B (bar 44-58) - Interlude (bar 58 -66) - Transition (bar 67-86) - Part B '(bar 87-101) - Postlude (bar 101-111). In this work, there are many changes in tempo and dynamic signs to support the atmosphere of Anoman Obong's story and tragedy. The results show that this work can transform a previously simple vocal song into a more complex choir.
} 


\section{PENDAHULUAN}

Paduan suara atau kor (dari bahasa Belanda, koor) merupakan istilah yang merujuk kepada ansambel musik yang terdiri atas penyanyipenyanyi maupun musik yang dibawakan oleh ansambel tersebut. Umumnya suatu kelompok paduan suara membawakan musik paduan suara yang terdiri atas beberapa bagian suara (bahasa Inggris: part, bahasa Jerman: Stimme) (Tambajong, 1992).

Salah satu jenis / genre yang akan dianalisis oleh penulis adalah paduan suara rakyat / folklore. Kata folklor merupakan pengindonesiaan dari bahasa Inggris folklore, berasal dari dua kata folk dan lore. Kata folk berarti sekelompok orang yang memiliki ciri pengenal fisik, sosial dan kebudayaan sehingga dapat dibedakan dari kelompok kelompok sosial lainnya. Ciri pengenal itu antara lain: warna kulit, bentuk rambut, mata pencaharian, dsb. Kata lore merupakan tradisi dari folk, yaitu sebagian kebudayaan yang diwariskan secara lisan atau melalui salah satu contoh yang disertai dengan gerak isyarat atau alat bantu pengingat (Tambajong, 1992). Maka bisa disimpulkan bahwa folklore adalah bagian dari kebudayaan yang disebarkan atau diwariskan secara tradisional baik dalam bentuk lisan maupun contoh yang disertai isyarat atau alat bantu pengingat.

Adapun ciri-ciri folklor adalah penyebaran dan pewarisannya ditulis secara lisan, bersifat tradisional, bersifat anonim, memiliki fungsi penting dalam kehidupan masyarakat, selain sebagai hiburan, pendidikan nilai, menyampaikan proses sosial dan untuk menyampaikan keinginan yang terpendam / wasiat, merupakan milik bersama masyarakat pendukungnya.

Paduan suara lagu rakyat (folklore) adalah paduan suara yang menyajikan lagu-lagu rakyat atau tradisional dari berbagai daerah di dunia. Salah satunya adalah lagu Anoman Obong, yaitu lagu yang telah dikenal luas di masyarakat Jawa khususnya dan Indonesia pada umumnya. Ranto Edy Gudel merupakan seniman dan pencipta lagu asal Solo yang akhir 2002 lalu tutup usia. Lagu Anoman Obong ciptaan Ranto pada 1996 silam itu berhasil dibawakan OM Ken Arok secara fenomenal dan populer hingga kini.

Salah satu aranger yang mengaransemen lagu ini adalah V. Mangunsongs. Beliau telah mengaransemen lagu anoman obong menjadi bentuk paduan suara dewasa SATB. Aransemen ini telah dinyanyikan di banyak perlombaan dan festival paduan suara tingkat nasional maupun internasional dan meraih banyak prestasi lewat aransemen ini. Maka dari itu penulis sangat tertarik untuk menganalis bentuk dan struktur aransemen lagu anoman obong yang diaransemen oleh $\mathrm{V}$. Mangunsongs yang notabene beliau pernah mendapat gelar best conductor di ajang Hainan Choir Festival, China.

Karya dan aransemen musik sudah banyak diteliti dari berbagai unsur seperti struktur dan bentuk musiknya. Namun untuk analisis aransemen paduan suara masih sulit ditemukan. Dari data yang diperoleh, aransemen paduan suara lagu anoman obong karya V. Mangunsongs belum pernah menjadi sebuah objek penelitian sehingga perlu adanya penelitian mengenai bentuk aransemennya.

METODE

Pendekatan dalam penelitian ini menggunakan pendekatan kualitatif karena hasil dan data yang akan diperoleh bersifat kualitatif dan dalam bentuk keterangan atau gambaran tentang kejadian dan kegiatan secara konseptual, menyeluruh dan bermakna. Strauss mengatakan bahwa penelitian kualitatif merupakan jenis penelitian yang temuan-temuannya tidak diperoleh melalui prosedur statistik atau bentuk hitungan lainnya. Bogdan dan Taylor (Sumaryanto, 2007) mendefinisikan penelitian kualitatif sebagai prosedur penelitian yang menghasilkan data deskriptif berupa kata-kata tertulis atau lisan dari orang-orang dan perilaku yang dapat diamati. Sugiyono (Sugiyono, 2007) menyimpulkan "Metode penelitian kualitatif adalah metode penelitian yang berlandaskan pada filsafat postpositivisme, digunakan untuk meneliti pada kondisi obyek yang alamiah, (sebagai lawannya adalah eksperimen) dimana penulis adalah sebagai instrumen kunci, pengambilan sampel sumber data dilakukan secara purposive dan snowbaal, teknik pengumpulan dengan triangulasi (gabungan), analisis bersifat induktif/kualitatif, dan hasil penelitian kualitatif lebih menekankan makna daripada generalisasi".

Penelitian ini menggunakan metode analisis isi (content analysis). Kriyantono (Kriyantono, 2012) menyatakan analisis isi adalah teknik yang dapat digunakan peneliti untuk mengkaji perilaku menusia secara tidak langsung melalui analisis terhadap komunikasi mereka seperti : buku teks, esay, koran, novel, artikel, majalah, lagu, gambar iklan dan semua jenis komunikasi yang dapat dianalisis. Analisis isi adalah alat penelitian yang difokuskan pada konten aktual dan fitur internal media. Hal ini digunakan untuk menentukan 
keberadaan kata-kata tertentu, konsep, tema, frase, karakter atau kalimat dalam teks atau serangkaian teks. Teks dapat didefinisikan secara luas sebagai buku, bab buku, esay, wawancara, diskusi, tajuk berita dan artikel surat kabar, dokumen sejarah, pidato, percakapan, iklan, atau dalam bentuk dokumen (Kholil, 2006).

Oleh karena itu penelitian kualitatif dengan metode analisis isi sangat cocok untuk membedah bentuk aransemen lagu Anoman Obong ciptaan Ranto Edi Gudel untuk paduan suara karya V. Mangunsongs.

\section{HASIL DAN PEMBAHASAN}

Hasil penelitian Kurniawan (Kurniawan \& Suharto, 2019) tentang peran pelatih paduan suara sangat signifikan dalam membangun sebuah tim, sedangkan penelitian Ratna (Strinariswari, R., Susetyo, B., \& Raharjo, 2015) tentang strategi pembelajaran ekstrakurikuler Paduan Suara sangat dapat dipakai sebagai rujukan dalam mengelola grup paduan suara. Sementara itu, untuk mengaransemen lagu Anoman Obong ke dalam sebuah bentuk aransemen paduan suara maka V. Mangunsongs mempelajari terlebih dahulu lagu aslinya yaitu Lagu Anoman Obong yang diciptakan oleh seniman asal Solo bernama Ranto Edi Gudel dengan melihat karakteristik lagunya. Menurut V. Mangunsongs, kekuatan lagu yang dimiliki oleh lagu Anoman Obong yaitu terletak pada karakter lagu yang energik dan unik dimana pada lagu aslinya memunculkan unsur jaipong, sunda, langgam dan keroncong.

Setelah V. Mangunsong mempelajari karakteristik lagu asli Anoman Obong, V. Mangunsong menyusun konsep pengembangan aransemen lagu Anoman Obong dengan memperhatikan detail lagu. Selanjutnya V. Mangunsongs membuat grand design dengan kerangka bentuk aransemennya yaitu meliputi introduksi, verse, refrain, transisi, interlude dan coda. Penyususnan konsep pengembangan ini dilakukan dengan cara trial and error dengan memperhatikan penempatan suasana lagu karena dalam mengaransemen lagu Anoman Obong ini V. Mangunsongs ingin membuat karya paduan suara yang mengombinasikan cerita dan tragedi Anoman Obong ke dalam bentuk paduan suara.

Aransemen lagu Anoman Obong ciptaan Ranto Edi Gudel untuk paduan suara karya V. Mangunsongs ini merupakan lagu daerah / folklore karena aransemen yang akan dibuat menggunakan bahasa daerah dan menggunakan idiom suara alat musik tradisional jawa. Nada dasar yang digunakan dalam aransemen ini adalah nada dasar $\mathrm{E}$ minor dengan tempo dasar c.a 82. Jenis suara yang digunakan adalah terdiri dari Sopran Solo, Sopran 1, Sopran 2, Alto 1, Alto2, Tenor 1, Tenor 2, Bass 1 dan Bass 2.

Introduksi (birama 1-24 dengan tanda nada E minor)

Introduksi dibuka dengan suara Bass, Alto, Tenor dan Sopran pada birama 1 dengan susuk menyusul. Masing-masing suara menggunakan motif yang sama dan menggunakan gradasi ekspresi f pada Bass, f pada Alto, kemudian ff pada Tenor kemudian diakhiri fff dan tanda fermata pada Sopran, Tenor, Alto dan Bass secara bersamasama.

Penggunaan kata 'kobong' yang berarti 'terbakar' dalam Bahasa Indonesia menjadi awalan yang cocok untuk menggambarkan suasana dan cerita yang akan disampaikan lagu Anoman Obong karena kata kobong sering dipakai di bagian-bagian selanjutnya.

Pada birama 2-12 adalah Intoduksi section I dengan melodi utama pada Solo Sopran dengan tanda tempo 68. Tanda ekspresi yang digunakan Solo Sopran adalah mp sedangkan Sopran, Alto, Tenor dan Bass berlaku sebagai pengiring dengan menyanyikan idiom gamelan secara konstan dari birama 2 sampai birama 11. Bass 1 dan Bass 2 menyanyi unisono dengan motif yang sama yaitu dengan notasi penuh dengan lirik 'gung' sebagai suara gong dalam gamelan. Alto 1, Alto 2, Tenor 1 dan Tenor 2 menyanyikan harmoni dengan motif yang sama dengan 3 not perempatan di setiap birama dengan lirik 'ning nang ning'. Sopran 1 dan Sopran 2 mengisi iringan dengan interlocking notasi setengah, seperempat dan seperdelapan dimana lirik yang dinyanyikan oleh Sopran 1 adalah 'ting ting ting ting ting' dan Sopran 2 adalah 'ning nang ning gung ning nang ning'.

Introduksi section 2 menggambarkan suasana gaduh dan mencekam yang ditandai dengan lirik 'bong kobong' pada Sopran 1, Sopran 2, Alto 1, Alto 2 dan Tenor 1 serta lirik 'gung ding gung' pada Tenor 2, Bass 1 dan Bass 2. Kombinasi dari ritmis yang beragam dan bersahut-sahutan serta tempo Allegro membuat suasana lagu pada bagian ini lebih mencekam dan gaduh.

Introduksi section 2 dimulai pada birama 13 dengan tanda mula $\mathrm{E}$ minor dan bertempo Allegro. Cantus firmus (Stein, 1979)dinyanyikan oleh Tenor 1 pada birama 16-19. Penggunaan tangga nada kromatis pada melodi utama memberi kesan kegaduhan yang terjadi dengan background pengiring yang menyanyikan lirik 'kobong' dengan motif ritmisnya masing-masing. Bass 1, Bass 2 dan 
Tenor 2 tetap menjadi pengiring dengan motif yang berbeda dari section 1 dengan lirik 'gung ding ding ding gung' yang diulang-ulang. Sopran 1 dan Sopran 2 juga mulai mengiringi pada birama 16 dengan sekuen naik pada Sopran 1 pada birama 18 dengan lirik 'bong bong bong bong kobong'.

Semua suara motif ritmis yang sama dengan nilai notasi seperenambelasan dan seperdelapanan pada birama 20 dan 21. Penggunaan lirik 'bong kobong kobong' secara cepat membuat suasa lebih tegas dan mencekam. Namun suasana dikembalikan lagi menjadi tenang dengan tanda decrescendo yang ada di birama 24. nada $\mathrm{E}$ minor)

Bagian A (birama 25-35 dengan tangga

Pada birama 25 sampai birama 29 semua menyanyikan sekaligus menceritakan awal mula Dewi Sinta diculik oleh Rahwana dengan melodi utama dinyanyikan bersama-sama secara unisono (birama 25-28 dinyanyikan unisono kemudian masing-masing berubah pada birama 29) oleh Sopran 1, Sopran 2, Alto 1, Alto 2, Tenor 1, Tenor 2, Bass 1 dan Bass 2 dengan tanda ekspresi mf. Kemudian melodi utama berpindah ke Alto 1 dan Alto 2 pada birama 29 sampai 34 dan dinyanyikan dengan ekspresi $\mathrm{mf}$ sedangkan suara yang lain bertindak sebagai pengiring. Pada birama 35 terdapat dua repetisi motif dari bagian akhir melodi utama yaitu birama 34 sebagai akhir dari Bagian A.

Bagian A' (birama 35-43 dengan tangga nada $\mathrm{E}$ minor)

Bagian ini merupakan variasi dari tema lagu utama yaitu Bagian A. Melodi utama dinyanyikan oleh Sopran 1 dan Sopran 2 secara unisono. Terdapat variasi melodi pada bagian ini untuk memberikan suasana yang berbeda dari Bagian A. Contoh variasi melodi terdapat pada birama 38 yaitu dengan memberikan nada A\# yang sebelumnya pada Bagian A melodi utama tidak terdapat nada disonan.

Saat Sopran 1 dan Sopran 2 menyanyikan melodi utama Bagian A, suara yang lain yaitu Alto 1, Alto 2, Tenor 1, Tenor 2, Bass 1 dan Bass 2 bertindak sebagai pengiring dengan dengan membuat interlocking dengan melodi utama. Pengiring mengisi jeda atau nada panjang dari melodi utama dengan motif sinkopasi. Pengulangan lirik melodi utama oleh pengiring berfungsi untuk memperjelas apa yang sampaikan oleh melodi utama.

\section{E minor)}

Bagian B (birama 44-58 dengan tangga nada

Bagian B menceritakan Anoman yang dijatuhi hukuman dibakar hidup-hidup malah membebaskan diri dan tubuhnya tidak terbakar karena kesaktiannya. Setelah terbebas dari belenggu Indrajid, Anoman kemudian malah membakar seluruh istana dan kerajaan Alengka dengan api yang ada di tubuhnya. Gejolak api itu membakar dan menghanguskan semua bangunan yang menjadikan seluruh penduduk Kerajaan Alengka ketkutan.

Bagian B dimulai dari birama 44 dengan tanda crescendo. Semua suara bernyanyi serentak secara homofon sepanjang Bagian B dengan melodi utama pada Sopran 1 dan Sopran 2. Terdapat variasi melodi yang disisipkan pada birama 46 dan 47 secara unisono dan menggunakan nada kromatis untuk memberikan kesan kuat.

Pada birama 55 sampai 57 terdapat jembatan sebelum masuk ke Interlude. Melodi utama dinyanyikan Sopran 1 pada birama 55 dengan tanda rall yang menjadikan birama ini dan selanjutnya berangsur-angsur lembat dengan tanda decrescendo sebagai pengantar untuk masuk ke Interlude dengan tempo 82. Kemudian melodi utama, Sopran 1, disahut oleh suara Sopran 2, Alto 1, Alto 2, Tenor 1, Tenor 2, Bass 1 dan Bass 2 pada birama 56-57 dengan diakhiri akor $\mathrm{V}$.

\section{E minor)}

Interlude (birama 58-66 dengan tanda nada

Interlude dimulai pada birama 58 dengan imitasi suara alat musik tradisional yang dinyanyikan oleh Sopran 2, Tenor 1, Tenor 2, Bass 1 dan Bass 2. Suasana yang dibangun pada bagian interlude sangat berbeda dari bagian sebelumnya maupun sesudahnya karena adanya peranan imitasi suara alat musik tradisional yang dinyanyikan oleh Sopran 2, Tenor 1, Tenor 2, Bass 1 dan Bass 2. Kemudian terdapat penggunaan kata yang di tidak bermakna yang dinyanyikan dalam senandung melodi utama oleh Sopran 1 yaitu dengan lirik 'e yo ae ya e yo e yo ae' dan diiringi juga oleh Alto 1 dan Alto 2 dengan kata 'e ya e e ya e e'.

Alto 1 tetap bertindak sebagai suara manusia dengan kata 'e ya e e ya e e' dengan dipertebal oleh Alto 2. Sopran 2, Tenor 1 dan Tenor 2 saling mengisi dengan teknik interlocking dengan kata 'cing cing cing cing'. Bass 1 dan Bass 2 menyanyikan suara gong dengan kata 'gung' dan suara perkusi mirip suara maracas dengan diberi simbol cross dengan lirik 'ck ck ck'.

\section{E minor)}

Transisi (birama 67-86 dengan tanda nada

Transisi yang digunakan adalah transisi panjang yang dibagi menjadi tiga section sebelum masuk ke bagian selanjutnya. Transisi ini 
menggunakan kata 'kobong' lagi yang telah digunakan di introduksi. Suasana gaduh juga dimunculkan kembali mirip dengan Introduksi section 2 .

Transisi section 1 dimulai dari birama 67 dengan tanda birama $2 / 4$ dan tanda ekspresi $\mathrm{mf}$ yang menunjukan ada perubahan suasana dari interlude yang bertanda birama 4/4 dan bertanda ekspresi mp. Motif yang digunakan adalah triplet yang direpetisi sampai birama 69 dengan teknik arpeggio dan unisono yang menjadikan kesan kuat dan kontras dari bagian interlude. Pada birama 70 tanda biramanya berubah lagi menjadi 4/4 dengan tempo yang lebih cepat yaitu Allegro. Pada birama 70 sampai birama 72 juga menggunakan gradasi ekspresi dimulai dari $\mathrm{mp}, \mathrm{mf}$ dan $\mathrm{f}$ yang masing masing diikuti oleh tanda crescendo yang membuat kesan ekstrem untuk menuju ke section selanjutnya.

Trasisi section 2 menggambarkan kegaduhan yang terjadi di kerajaan Alengka karena Anoman membakar setiap sudut istana dan Kerajaan Alengka seperti yang telah dikisahkan pada Bagian B. Kegaduhan yang terjadi direprentasikan dengan kata 'kobong' menggunakan tanda ekspesi ff yang diulang-ulang sepanjang transisi section 2 ini oleh Sopran 1, Sopran 2, Alto 1 dan Alto 2. Terdapat kalimat tanya pada birama 73-74 dan kalimat jawab pada birama 75-76. Birama 73-75 diulang empat kali. Pada setiap akhir ulangan terdapat teriakan Alto 1, Alto 2 dan Tenor 2 dengan kata 'tulung' yang berarti 'tolong' dalam Bahasa Indonesia. Aksen ini menambah kesan kecemasan dan keteakutan yang dialami oleh penduduk kerajaan Alengka. Suara imitasi gong yang menggebu-gebu yang dinyanyikan oleh Tenor 2, Bass 1 dan Bass 2 menggunakan lirik 'gung ding gung' sahut menyahut menambah kesan gaduh yang terjadi.

Transisi section 3 dimulai pada birama 82 yang merupakan klimaks dari bagian transisi yang ditandai dengan tanda ekspresi yang belum pernah keluar pada bagian sebelumnya yaitu tanda ekspesi fff yang berarti bagian transisi section 3 dinyanyikan dengan sangat keras. Teknik homofon digunakan dalam transisi section 2 kemudian V. Mangunsongs menambah satu akord $F$ pada birama 84 yang mana belum pernah digunakan juga pada bagian sebelumnya untuk memberikan suasana yang berbeda.

Pengulangan dinyanyikan dua kali dimana terdapat perbedaan pada kalimat jawab yang terdapat pada kamar 1 dan kamar 2. Pada kamar 1 motifnya masih mengikuti birama sebelumnya namun ketika sudah memasuki pengulangan yang kedua dan masuk kamar dua, motifnya berubah dari sinkopasi menjadi ketukan rata bernilai $1 / 4$ dengan tanda decrescendo.

\section{Bagian B' (birama 87-101 dengan tanda nada $\mathrm{E}$ minor)}

Bagian B' adalah pengulngan Bagian B dengan variasi ritmis. Melodi utama dinyanyikan oleh Sopran 2 dengan tanda ekspresi mf. Sopran 1, Alto 1, Alto 1, Tenor 1, Tenor 2, Bass 1 dan Bass 2 bertindak sebagai pengiring melodi utama dengan mengisi jeda atau nada panjang melodi utama dan menjadi penebal melodi utama di beberapa bagian tertentu.

\section{E minor)}

Postlude (birama 10-111 dengan tanda nada

Bagian Postlude ini menjadi penutup aransemen dengan menggunakan kata 'kobong' lagi yang telah digunakan pada introduksi dan transisi. Kata 'kobong' yang berarti terbakar dalam Bahasa Indonesia ini menjadi topik utama dari cerita Anoman Obong. Oleh sebab itu pada bagian Postlude kata 'kobong' menjadi lirik utama dan menjadi rangkuman yang menceritakan kegaduhan kerajaan Alengka yang diluluhtantahkan oleh Anoman dengan api yang dibawanya.

Pada birama 101 sampai birama 106 suara Sopran 1, Alto 1, Alto 2, Tenor 1, Tenor 2, Bass 1 dan Bass 2 menyanyikan motif yang sama dengan homofon dengan menggunakan notasi seperenambelasan yang diakhiri dengan sinkopasi di setiap biramanya yang mana menjadikan bagian ini menggebu-gebu dan chaos. Tanda ekspresi yang digunakan juga dibuat agar ada gradasi dari mf pada birama 101, ff pada birama 103 dan fff pada birama 105 sehingga menimbulkan kesan semakin lama semakin keras.

Pada setiap akhir birama dari birama 101 sampai 105 Sopran 2 bertindak sebagai suara yang berteriak 'tulung kobongan' yang berarti 'tolong kebakaran' dalam Bahasa Indonesia. Aksen ini menambah suasana yang mencekam dan gaduh yang bersahut-sahutan dengan suara 'kobong' yang dinyanyikan oleh Sopran 1, Alto 1, Alto 2, Tenor 1, Tenor 2, Bass 1 dan Bass 2.

Pada birama 107 semua suara menyanyi dengan teknik arpeggio dan unisono dan pecah menjadi harmoni pada birama 110 . Tanda tempo yang digunakan berubah menjadi 82. Tanda ekspresi f pada birama 107 menjadi awal dari gradasi dan proses menuju ff dengan tanda crescendo. Kemudian suasana kembali naik dengan adanya tanda crescendo pada biara 109 dan 110 menuju birama 111 dengan kata 'kobong' dan tanda ekpresi fff sebagai penutup. 


\section{SIMPULAN}

Aransemen Lagu Anoman Obong ciptaan Ranto Edi Gudel untuk paduan suara karya V. Mangunsongs memiliki 111 ruang birama dengan bagian lagu Introduksi (birama 1-24) - Bagian A (birama 25-35) - Bagian A' (birama 35-43) - Bagian B (birama 44-58) - Interlude (birama 58-66) Transisi (birama 67-86) - Bagian B' (birama 87-101) - Postlude (birama 101-111). Terdapat 2 Section dalam Introduksi dan 3 section dalam Transisi.

Diangkat dari lagu Anoman Obong ciptaan Ranto Edi Gudel, tema lagu utama dimunculkan dengan berbagai pengembangan motif, variasi, dan pemanfaatan tanda ekspresi yang kaya. Walaupun di dalam karya ini hanya terdapat satu tangga mula E minor tanpa modulasi namun dengan banyaknya tanda dinamika dan perubahan tempo, aransemen lagu Anoman Obong ciptaan Ranto Edi Gudel untuk paduan suara karya V. Mangunsongs ini tetap menjadi garapan yang kompleks untuk ditampilkan di atas panggung.

Karya ini mentransformasikan lagu vokal solo menjadi lagu untuk paduan suara dari bentuk yang sederhana menjadi lebih kompleks dengan pengembangan dan variasi yang beragam. Aransemen ini menggunakan komposisi bebas yang terdiri dari beberapa bagian dimana di setiap bagiannya mempunyai suasana. V. Mangunsongs menyususun aransemen ini dari Introduksi sampai Postlude benar-benar memperhatikan alur cerita dan suasana epos Ramayana dengan permainan ritmis, dinamika, ekspresi dan lirik secara berurutan. Kepiawaian V. Mangunsongs dalam mengaransemen lagu Anoman Obong membuat keberagaman suara dapat dikemas dengan baik.

\section{DAFTAR PUSTAKA}

Kholil, S. (2006). Metodologi Penelitian Komunikasi. Cita Pustaka Media.

Kriyantono, R. (2012). Teknik Praktis Riset Komunikasi (6th ed.). Kencana. Prenadamedia Group.

Kurniawan, C., \& Suharto, S. (2019). Peran Pelatih Dalam Membangun Pelatihan Paduan Suara Yang Menyenangkan Di Paduan Suara Voice Of Conversation (VOC) UNNES. Jurnal Seni Musik, $8(1)$. https://doi.org/https://doi.org/10.15294/js m.v8i1.29207

Stein, L. (1979). Structure \& Style. The Study and Analysis of Musical Form. Summy-Birchard
Music:Princeton

Strinariswari, R., Susetyo, B., \& Raharjo, E. (2015). Strategi Pembelajaran Ekstrakurikuler Paduan Suara DI Smp Negeri 2 Jepara. Jurnal Seni Musik, 4(1).

Sugiyono. (2007). memahami Penelitian Kualitatif. CV Alfabeta.

Sumaryanto, T. F. (2007). Pendekatan Kuantitatif dan Kualitatif dalam Penelitian Pendidikan Seni. Unnes Press.

Tambajong, J. (1992). Ensiklopedia Musik. PT. Cipta Adi Pusaka. 